\title{
Pulmonary Mechanics during Pregnancy*
}

\author{
J. Bernard L. Gee, $\nmid$ Bernard S. Packer, $\ddagger$ J. Eugene Millen, and E. D. Robin \\ (From the Department of Medicine, University of Pittsburgh School of Medicine, \\ Pittsburgh, Pa.)
}

\begin{abstract}
Summary. Previously reported changes in static lung volumes during pregnancy have been confirmed.

Measurements of lung compliance $\left(C_{L}\right)$ and total pulmonary resistance $\left(R_{L}\right)$ were made in 10 women in the last trimester of pregnancy and 2 months postpartum, employing an esophageal balloon and recording spirometer. $C_{L}$ was unaffected by pregnancy, but $\mathrm{R}_{\mathrm{L}}$ was $50 \%$ below normal during pregnancy.

Measurements of airway conductance $\left(\mathrm{C}_{\mathrm{A}}\right)$ were made, employing the constant pressure body plethysmograph on 14 nonpregnant and 13 pregnant women. Specific airway conductance was increased during pregnancy.

Serial measurements of $\mathbf{C}_{\boldsymbol{A}}$ indicated a progressive increase beginning at about 6 months of gestation and a return to normal by 2 months postpartum.

The mechanism of the increased $C_{A}$ during pregnancy is not known. It may be related to changes in bronchial smooth muscle tone and conceivably explains the tolerance of certain patients with lung resections to pregnancy.
\end{abstract}

\section{Introduction}

The mechanical properties of the lungs in pregnant women are of interest for several reasons. First, there is a conflict between the complaints of dyspnea made by many women during pregnancy and the remarkably benign clinical course shown by women with pulmonary resections during pregnancy (1). Secondly, detailed spirometric studies, notably by Cugell, Frank, Gaensler, and Badger (2), have indicated a progressive reduction in the functional residual capacity (FRC) and expiratory reserve volume (ERV) as term approaches. The reduction in the resting lung volume might be expected to be associated with an increase in airway resistance $\left(R_{\mathbf{A}}\right)$, which is known to be volume dependent (3). This reduction in FRC is in contrast with the preservation of the vital capacity (VC). The preservation

\footnotetext{
* Submitted for publication November 7, 1966; accepted February 17, 1967.

This work was supported in part by grant HE-05059 from the National Institutes of Health and in part by a grant from the Tuberculosis League of Pittsburgh.

$\dagger$ Address requests for reprints to Dr. J. Bernard L. Gee, Dept. of Medicine, University of Pittsburgh School of Medicine, Pittsburgh, $\mathrm{Pa} .15213$.

$\ddagger$ Fellow of the Pennsylvania Thoracic Society.
}

of $\mathrm{VC}$ suggests that lung compliance $\left(\mathrm{C}_{\mathrm{L}}\right)$ is not greatly changed. Third, metabolic changes occurring in pregnant women might modify pulmonary mechanics. Hypocapnia occurs during pregnancy (4), and this is known to increase airway resistance (5). However, hormone-determined changes in smooth muscle tone and possibly connective tissue elastance might occur during pregnancy and so could possibly alter the mechanical properties of the respiratory system.

Although there are extensive observations of many aspects of respiration during pregnancy (6), there are no published studies of the effects of pregnancy on lung compliance $\left(C_{L}\right)$ and only one report ( 7 ) indicating a reduction in total pulmonary resistance $\left(R_{L}\right)$ demonstrated by the interruptor method.

\section{Methods}

Lung volumes were determined on a 9-L Collins spirometer. FRC was measured by the helium dilution method.

Pulmonary mechanics. Lung compliance was measured by the method of Neergard and Wirz (8) employing a model 370 wedge spirometer (Med-Science Electronics) to monitor volume and flow. The wedge spirometer provides electrical calibrations for volume and flow. These were periodically checked with a Collins 9-L spirometer 


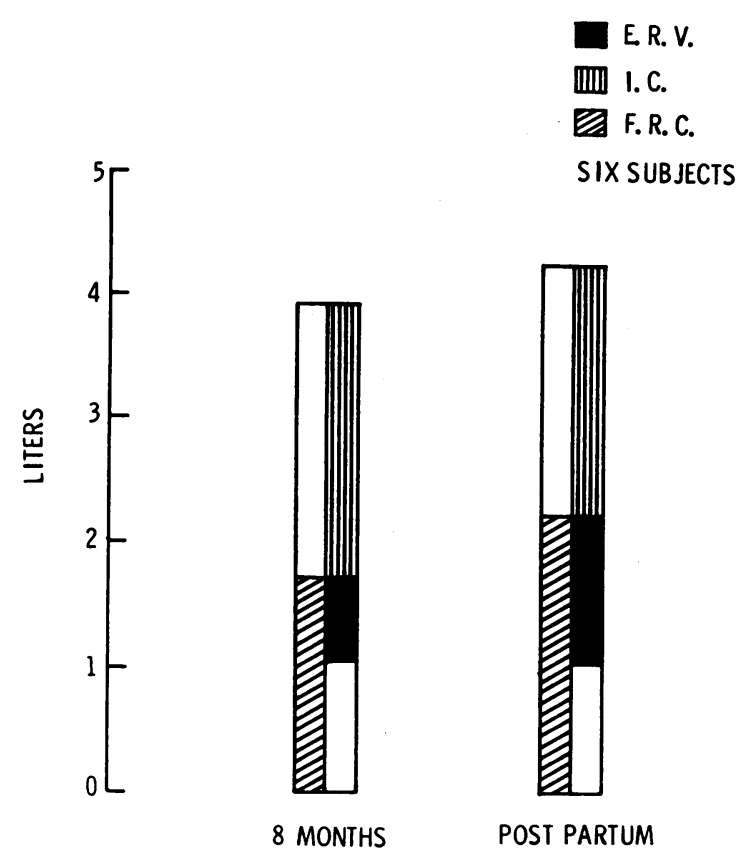

Fig. 1. A comparison of the Static LUNG volumes AT THE EIGHTH MONTH OF PREGNANCY AND POSTPARTUM. $\mathrm{ERV}=$ expiratory reserve volume; IC $=$ inspiratory capacity ; FRC = functional residual capacity.

for volume and a Rotameter flowmeter to provide constant flows of up to $6 \mathrm{~L}$ per second, whose values were predetermined volumetrically. Transpulmonary pressure was obtained by using an esophageal latex rubber balloon, $10 \mathrm{~cm}$ in length and $3 \mathrm{~cm}$ in circumference, a PE 160 catheter, and Sanborn 270 pressure transducer. Recordings were made on an Electronics for Medicine recorder. The balloon was positioned to obtain the highest negative end expiratory pressure and contained $1 \mathrm{ml}$ of air. Measurements of $C_{L}$ were obtained during breathing by comparing pressure and volume changes at points of zero flow. $C_{\mathbf{L}}$ was studied during normal quiet breathing at FRC.

Total lung resistance was calculated by the isovolume method, which relates changes in pressure to changes in flow at constant volume (8).

Airway resistance was measured in a constant pressure body plethysmograph, designed by Mead (9). Volume was measured by a Krogh spirometer and Linearsyn transducer. Flow was measured by a heated wire mesh screen pneumotachograph and Statham PL-5 pressure transducer. A linear response was obtained up to flow rates of $2.5 \mathrm{~L}$ per second. Mouth pressure was obtained from a Sanborn 270 pressure transducer. Flow and volume or pressure and volume were observed on the $x-y$ screen of an Electronics for Medicine recorder. The resistance of the circuit was $0.2 \mathrm{~cm} \mathrm{H}_{2} \mathrm{O}$ per $\mathrm{L}$ per second. The procedures for measuring $R_{\mathbf{A}}$ are as follows: The subject was comfortably seated in the plethysmograph while temperature stabilization occurred. Panting res- pirations at flow rates of about $1.0 \mathrm{~L}$ per second were begun to obtain flow/volume slopes on the $\mathbf{x}-\mathbf{y}$ recorder. An airway interruptor was then closed while panting continued against the shutter to obtain pressure/volume slopes. $\mathbf{R}_{\mathbf{A}}$ and total gas volume (assumed to be intrathoracic) were calculated by the method of DuBois (3), from the ratio of the two slopes and the appropriate calibration factors. Six measurements were obtained at the subject's resting lung volume. Additional measurements of $R_{A}$ were obtained at progressively larger volumes, and finally at volumes below the resting lung volumes.

Subjects were nursing and secretarial staff, aged 20 to 25 years, who had no history of pulmonary disease and were free from upper respiratory infections at the time of testing. No attempt was made to match pregnant and nonpregnant women for body size. All but one of the pregnant women were primigravida.

Types of studies. Four types of comparison were made. (The willingness of some pregnant women to perform all the studies proved limited, and, therefore, the comparative groups are somewhat variable.) 1) Lung volume measurements only were made in 6 separate subjects. 2) Lung compliance and total pulmonary resistance were studied in 10 subjects during pregnancy and after delivery. 3) Airway resistance was compared in 14 control and 13 pregnant women. Five of these pregnant subjests were also studied by comparison 2 ; the other 8 were unwilling to swallow the balloon. 4) The serial changes in airway resistance during pregnancy were followed in 6 subjects. In 5 of these, comparisons 2 and 3 were also completed. In the other 1 , only data for the serial studies were obtained. Where only 1 technique was employed, the procedure outlined for each method was followed. Where both balloon and plethysmography were used, the esophageal pressure method was employed first.

\section{Results}

Lung volumes. In a separate pilot study, static lung volumes alone were measured in 6 subjects who were about 8 months pregnant and then 2 months postpartum. The data are indicated in Figure 1, where the average of the 6 subjects is indicated. During late pregnancy, there is a $25 \%$ reduction in FRC and about $40 \%$ reduction in ERV. Slight and statistically insignificant reductions in total lung capacity and VC were also found. VC is maintained by the increase in inspiratory capacity. The changes were consistent in all subjects. These data agree with the more extensive studies of Cugell and his associates (2) in 19 subjects.

Airway resistance. In clinical practice the term $\mathrm{R}_{\mathbf{A}}$ is more commonly used than its reciprocal, $\mathrm{C}_{\mathbf{A}}$. However, $C_{A}$ bears a near linear relationship to 
the lung volume (3). The use of $\mathrm{C}_{\mathbf{A}}$ has two advantages. First, comparisons of the relationship between $C_{A}$ and the resting lung volumes without reference to the subject's body size may be made. This is accomplished by expressing the data as $\mathrm{C}_{\mathrm{A}} / \mathrm{L}$ of lung volume, the so-called specific airway conductance. Anthropometric factors determine $C_{A}$ by their relation to lung volumes (e.g., FRC). The use of specific $C_{A}$ therefore permits an estimate of airway conductance adjusted for body size. Second, direct comparisons may be made of the rate of rise in $C_{A}$ as the lung is voluntarily inflated.

The first comparison of $\mathrm{C}_{\mathbf{A}}$ between pregnant and nonpregnant women is shown in Figure 2, which indicates the specific airway conductance in 2 groups, namely, 14 control women and 13 pregnant women of similar age. The values in the pregnant women were obtained at a mean of $7 \frac{1}{2}$ months of gestation. When pregnant subjects were studied serially, the data obtained nearest to term were employed. These values for specific $\mathrm{C}_{\boldsymbol{A}}$ were obtained from $\mathrm{C}_{\mathrm{A}}$ and volume data observed at resting lung volumes. The use of such data obtained near FRC is important to minimize the between-groups variations in the regression slope relating $\mathrm{C}_{\mathbf{A}}$ to lung volume. The data indicate that, although there are considerable within-group variations, the mean specific $\mathrm{C}_{\mathbf{A}}$ of pregnant
$\Delta$

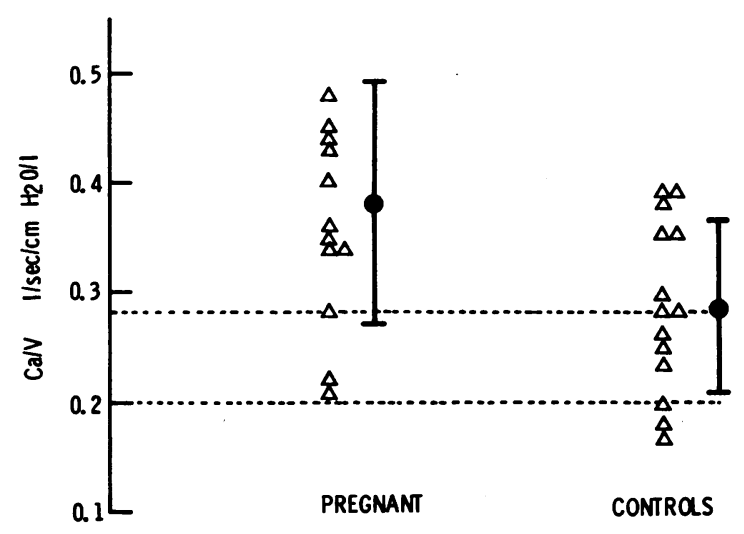

Fig. 2. A COMPARISON OF SPECIFIC AIRWAY CONDUCTANCE $\left(\mathrm{C}_{\mathrm{A}}\right)$ IN PREGNANT AND NONPREGNANT WOMEN. $\mathrm{V}=$ lung volume. Broken lines indicate the normal range.

women is $36 \%$ higher than the mean specific $\mathrm{C}_{A}$ of nonpregnant women $(\mathrm{p}<0.05)$. The mean specific $\mathrm{C}_{\mathbf{A}}$ in the control group is within the normal range of 0.20 to 0.28 reported by DuBois (3).

An evaluation of the differences in the regression relation between $C_{A}$ and lung inflation in these two groups is shown in Figure 3. Only those subjects in both groups whose lung volume ranges during airway resistance studies exceeded $1.5 \mathrm{~L}$ have been employed, yielding data on 9 control and 8 preg-
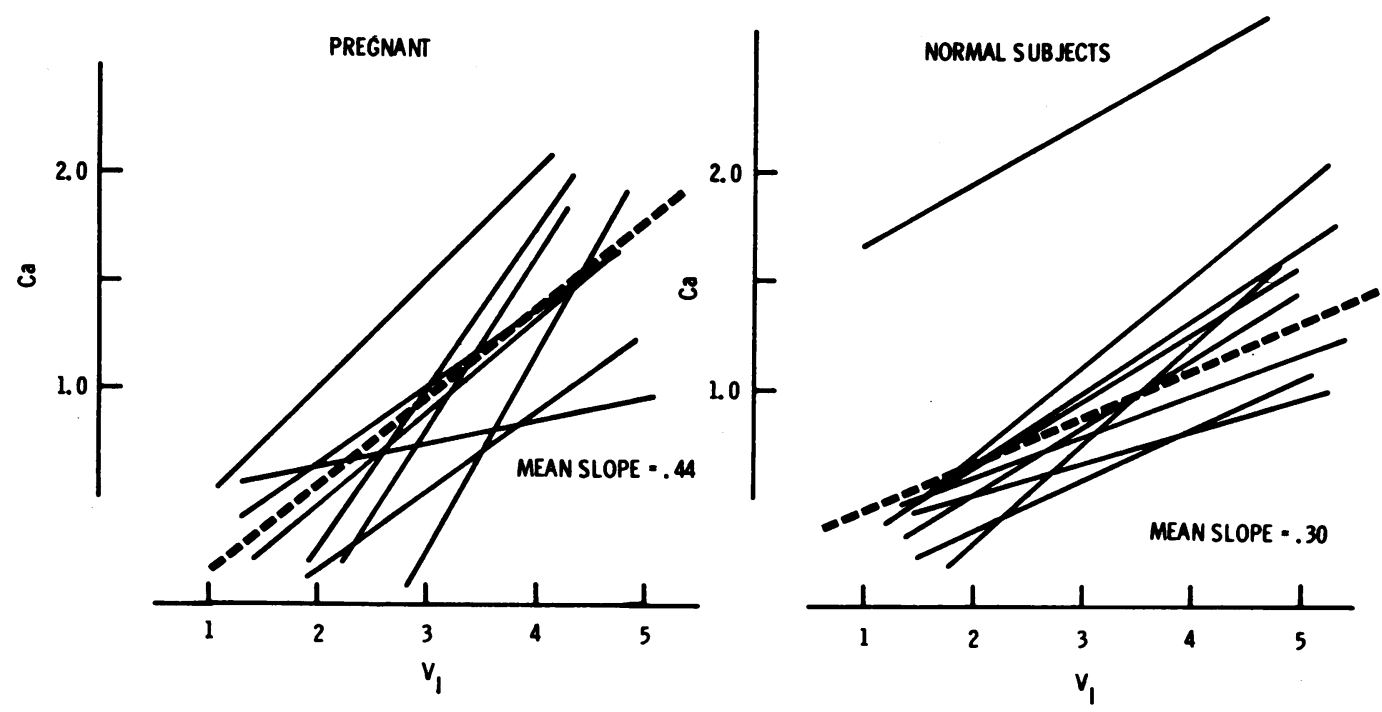

Fig. 3. A comparison betWeen the REgression lines Relating $C_{A}$ to $V_{L}$ in PREgNant and NonPREGNANT WOMEN. Solid lines represent the regression lines for each subject. Broken lines represent the mean of the slopes in each group. 


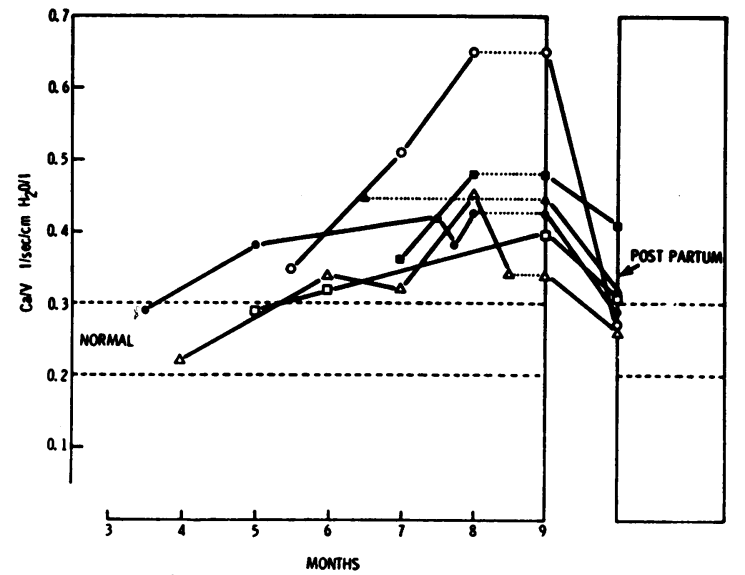

Fig. 4. Time course of SPECIFIC $C_{A}$ DURING PREGNANCY IN 5 sUBJECTs. Dotted lines are constructional and join the last observation during pregnancy to the 9-month vertical to permit comparison with the postpartum data.

nant women. This lung volume range requirement was necessary to permit the calculation by the method of least squares of the regression coefficient between $C_{\mathbf{A}}$ and lung volume for each subject. The Figure indicates the calculated regression lines. The data found in control subjects showed a mean slope of $0.30 \pm 0.10$, which compares with the normal range reported by DuBois of 0.13 to 0.35 (3). The mean slope of the pregnant women was $0.44 \pm 0.28$. These slopes were compared by the Student $t$ test and were significantly different $(p<0.01)$. Thus, during pregnancy, there is an unusually large increase in $\mathrm{C}_{\mathbf{A}}$ as the lung is progressively inflated.

Time course of the change in airway conductance. In 6 pregnant women, serial observations of the specific airway conductance were made. These data are shown in Figure 4, which indicates the specific $\mathrm{C}_{\boldsymbol{A}}$ during pregnancy and postpartum (4 to 6 weeks after delivery). There is a rise in specific $C_{\mathbf{A}}$, particularly in the third trimester of pregnancy, with a striking return to normal by about 5 weeks after delivery. The exact time course of specific $C_{A}$ after delivery is not known, since it was not practical to obtain studies in the immediate postpartum period.

Lung compliance and total pulmonary resistance. The measurement of $C_{L}$ and $R_{L}$ by the esophageal balloon technique depends on the assumption that during breathing, the changes in intrapleural and esophageal pressures are equal. The direct comparison is clearly impossible in pregnant normal subjects, but some information may be obtained from a consideration of end expiratory pressures (EEP) during tidal breathing at FRC. Table I includes a comparison in 10 women between the values of EEP in the third trimester of pregnancy and about 5 weeks postpartum. The postpartum values are, in general, negative with a mean of $-2.7 \mathrm{~cm} \mathrm{H}_{2} \mathrm{O}$. These are within the reported normal ranges. However, during pregnancy a striking difference is observed. The EEP as measured in the balloon is positive, with a mean of $+1.7 \mathrm{~cm} \mathrm{H}_{2} \mathrm{O}$. This positive esophageal pressure cannot equal true transpulmonary pressure at a moment where there is no gas flow. Thus, the assumption that changes in esophageal pressure still reflect changes in transpulmonary pressure is required, if estimates of $C_{\mathbf{L}}$ are to be derived. A somewhat similar assumption is, of course, needed for the calculation of $R_{L}$ by the isovolume method. The estimates of $C_{L}$ and $R_{L}$ are indicated in Table I and were derived on the basis of these assumptions. To the extent that such calculations are valid (see Discussion), our data indicate that, although $\mathrm{C}_{\mathrm{L}}$ does not change, there is a highly significant change in $R_{L}(p<0.01)$. The mean $R_{L}$ during pregnancy is half that observed postpartum.

TABLE I

A comparison of end expiratory pressures (EEP), lung compliance $\left(C_{\mathrm{L}}\right)$, and total pulmonary resistance $\left(R_{\mathrm{L}}\right)$ in 10 subjects during pregnancy and postpartum

\begin{tabular}{|c|c|c|c|c|c|c|c|}
\hline \multirow[b]{2}{*}{$\begin{array}{c}\text { Subject } \\
\text { no. }\end{array}$} & \multicolumn{3}{|c|}{ Pregnant } & \multicolumn{4}{|c|}{ Postpartum } \\
\hline & EEP & $C_{L}$ & $\mathbf{R}_{\mathbf{L}}$ & EEP & $\mathrm{C}_{\mathbf{L}}$ & $\mathbf{R}_{\mathbf{L}}$ & $\begin{array}{c}\text { Predicted } \\
\mathrm{CL}_{\mathbf{L}} \dagger\end{array}$ \\
\hline & $\stackrel{\mathrm{cm}}{\mathrm{H}_{2} \mathrm{O}}$ & $\begin{array}{r}\mathrm{L} / \mathrm{cm} \\
\mathrm{H}_{2} \mathrm{O}\end{array}$ & $\underset{\mathrm{Cm} / \mathrm{sec}}{\mathrm{cm}}$ & $\stackrel{\mathrm{cm}}{\mathrm{H}_{2} \mathrm{O}}$ & $\begin{array}{r}\mathrm{L} / \mathrm{cm} \\
\mathrm{H}_{2} \mathrm{O}\end{array}$ & $\begin{array}{c}\mathrm{cm} \mathrm{H}_{2} \mathrm{O} / \mathrm{sec} \\
\end{array}$ & $\begin{array}{c}\mathrm{L} / \mathrm{cm} \\
\mathrm{H}_{2} \mathrm{O}\end{array}$ \\
\hline 1 & 4.2 & 0.13 & 0.2 & -3.1 & 0.13 & 2.3 & 0.14 \\
\hline 2 & 2.7 & 0.11 & 1.5 & -4.4 & 0.11 & 0.8 & 0.12 \\
\hline 3 & 1.2 & 0.12 & 1.2 & -8.6 & 0.14 & 1.9 & 0.17 \\
\hline 4 & 3.1 & 0.16 & 0.5 & -3.0 & 0.19 & 2.1 & 0.13 \\
\hline 5 & 1.5 & 0.09 & 0.7 & -2.5 & 0.13 & 1.7 & 0.14 \\
\hline 6* & 2.2 & 0.14 & 0.9 & -0.6 & 0.11 & 2.0 & 0.15 \\
\hline $7 *$ & -0.8 & 0.23 & 1.1 & -1.5 & 0.22 & 1.8 & 0.15 \\
\hline $8 *$ & 2.2 & 0.13 & 0.8 & +1.2 & 0.13 & 3.2 & 0.15 \\
\hline 9* & -0.1 & 0.21 & 0.5 & -3.2 & 0.20 & 1.0 & 0.18 \\
\hline $10 *$ & 0.9 & 0.09 & 1.2 & -1.2 & 0.20 & 1.5 & 0.16 \\
\hline$\underset{\text { SD }}{\text { Mean }}$ & 1.7 & $\begin{array}{l}0.14 \\
0.047\end{array}$ & $\begin{array}{l}0.9 \\
0.39\end{array}$ & -2.7 & $\begin{array}{l}0.16 \\
0.042\end{array}$ & $\begin{array}{l}1.8 \\
0.47\end{array}$ & 0.15 \\
\hline
\end{tabular}

* Subjects shown in serial studies in Results under "airway resist-

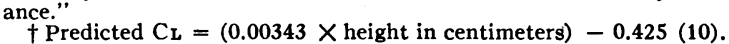




\section{Discussion}

\section{Esophageal pressure during pregnancy}

Before indicating the significance and possible mechanisms of these findings, we should discuss the validity of the esophageal balloon pressure changes as measures of changes in transpulmonary pressures during pregnancy. The following technical considerations apply: 1) Every effort was made to position the balloon in the midesophagus; 2) cardiac impulses were clearly visible in the records; these impulses show the usual amplitude of about $0.5 \mathrm{~cm} \mathrm{H}_{2} \mathrm{O} ; 3$ ) the balloon was not over distended, since only 1 $\mathrm{ml}$ of air was introduced into the balloon; 4) in two subjects (No. 6 and 7) in whom serial studies were performed during pregnancy, progressive rises in EEP occurred from -4.5 and -2.5 at 28 weeks to values at 36 weeks of -0.1 and -0.8 $\left.\mathrm{cm} \mathrm{H}_{2} \mathrm{O} ; 5\right)$ no excessive esophageal contractions were evident in the records; 6 ) the normal range of EEP in the postpartum women argues that balloon positioning was correctly performed in the postpartum state. Thus, it appears that a positive EEP during pregnancy is not due to the use of an improper technique, but reflects a genuine disparity between the esophageal and intrapleural pressures during late pregnancy.

As discussed earlier, positive transpulmonary pressures cannot occur at end normal expiration, and, therefore, the measured esophageal EEP values cannot reflect the absolute transpulmonary pressures. This raises the problem as to the effect of these EEP values on calculated $C_{L}$ and $R_{L}$. We cannot directly compare intrapleural and esophageal pressures in pregnant women, but there is a highly relevant analogy between pregnancy and the supine posture. The analogy includes a positive resting EEP (11-13) in normal supine subjects, and, further, the supine posture is associated with an ascent of the diaphragm. An alteration from sitting to supine posture produces changes in lung volume profile similar to those encountered in pregnancy, including lowered FRC, increased IC, and a normal VC. More recently, Chiang and Lyons (14) studied the effects of a $45^{\circ}$ tilt towards the supine position. They showed that esophageal EEP changes from -3.74 to $-2.71 \mathrm{~cm} \mathrm{H}_{2} \mathrm{O}$ and that FRC falls by $200 \mathrm{ml}$ as a result of this tilt. The full $90^{\circ}$ tilt towards a supine posture was studied by Mead and Gaensler (12), who compared intrapleural and esophageal pressures. They showed that lying supine causes the directly measured end expiratory intrapleural pressure to change from -5.1 to $-1.1 \mathrm{~cm} \mathrm{H}_{2} \mathrm{O}$, while the end expiratory balloon pressure changes from -4.8 to $+2.7 \mathrm{~cm} \mathrm{H}_{2} \mathrm{O}$. Thus, the supine posture is associated with a lack of agreement between pleural and balloon static pressure differences. These authors concluded that "measurements of compliance in the tidal range would be factitiously low as measured from esophageal pressure in the supine position" (12). This point was further developed by Knowles, Hong, and Rahn (13) and separately by Ferris, Mead, and Frank (15), who showed differences in the static pressure-volume diagram in 2 postures when the esophageal balloon was employed for the measurement of transpulmonary pressure. Both groups indicate that the greatest differences exist in the lower half of lung volume, and agree that the apparent supine $C_{L}$ calculated from balloon pressures at small tidal volumes would appear to be about $25 \%$ less than sitting values. The range of the percentage change in $\mathrm{C}_{\mathrm{L}}$ between the two postures is 0 to $40 \%$ (15).

Our data indicate a normal postpartum $C_{L}$ evidenced by comparing the $\mathrm{C}_{\mathrm{L}}$ observed and that predicted from the subject's height (Table I). The apparent $C_{L}$ during late pregnancy is not statistically different, but the mean value is lower by $0.02 \mathrm{U}$, that is, $12 \%$ lower than postpartum. This change is of similar magnitude to the apparent change reported for the supine studies. Thus, if the analogy between pregnancy and the supine posture is valid, it may be concluded there is no change in $C_{L}$. This conclusion is supported by the preservation of the VC during pregnancy.

The isovolume method for the calculation of $R_{L}$ requires less discussion. The method does assume 1) that the elastic component of pleural pressure is constant for any lung volume, irrespective of the phase of respiration (i.e., no significant hysteresis) ; 2) that any differences between pleural and esophageal pressures are constant at a given lung volume; and 3) that the time constants of the lung are sufficiently rapid for pressure equalization. There are no reasons to question the applicability of assumptions 1 and 2 to pregnant women during quiet tidal breathing. The time 
constant derives from the product of $R_{L}$ and $C_{L}$. $C_{L}$ has been shown to be normal, and $R_{A}$, the larger component of $R_{L}$, is, in fact, decreased. The time constant of the lungs of pregnant women is, therefore, sufficiently rapid to validate assumption 3.

\section{Airway and total pulmonary resistance}

Total pulmonary resistance $\left(R_{L}\right)$ is known to include 2 components. The larger component is airway resistance $\left(R_{\mathbf{A}}\right)$, and the smaller one derives from tissue resistance. Thus, a comparison of $R_{L}$ to $R_{A}$ is pertinent. Two such comparisons are presented in Table II. Section A compares the two methods on all subjects who were studied by each method. This comparison is, at best, a general one since these mean data are derived from studies of $R_{A}$ and $R_{L}$ in groups that included different subjects. Section $B$ presents a better comparison since these data were obtained on the same subjects. This comparison indicates that approximately $80 \%$ of the reduction in $R_{L}$ during pregnancy derives from the reduction in $R_{\mathbf{A}}$. It is not possible to state whether the tissue-resistive component is altered during pregnancy since this component is too small for precise measurement. A third comparison between $R_{L}$ and $R_{A}$ is achieved by correlating the two measures on the same subjects. This may be shown by comparing the reciprocal of $R_{A}$, namely $C_{A}$, and $1 / R_{L}$. Figure 5 presents this comparison. The two methods correlate fairly well $(r=0.61, p<0.025)$, and the regression coefficient of $C_{A}$ on $1 / R_{L}$ is 0.77 , a value not significantly different from 1.0. $\mathrm{C}_{\mathrm{A}}$ in general exceeds $1 / R_{L}$ as would be required by the presence of an additional tissue-resistive component in $R_{L}$. This comparison again can only be approximate,

TABLE II

A comparison of total pulmonary resistance $\left(R_{\mathrm{L}}\right)$ and airzeay resistance $\left(R_{\mathrm{A}}\right)^{*}$

\begin{tabular}{cccccc}
\hline \hline & & $\begin{array}{c}\text { No. of } \\
\text { subjects }\end{array}$ & Pregnant & $\begin{array}{c}\text { Post- } \\
\text { partum }\end{array}$ \\
\hline \multirow{4}{*}{$\mathrm{A}$} & & & \multicolumn{2}{c}{$c m \mathrm{H}_{2} \mathrm{O} / \mathrm{L} / \mathrm{sec}$} \\
$\mathrm{B}$ & $\mathrm{R}$ & 10 & 0.9 & 1.8 \\
$\mathrm{~B}$ & $\mathrm{R}_{\mathrm{A}}$ & 1.3 & 0.9 & 1.1 \\
& $\mathrm{R}_{\mathrm{L}}$ & 5 & 0.9 & 1.9 \\
& $\mathrm{R}_{\mathrm{A}}$ & 5 & 0.7 & 1.5
\end{tabular}

* Group A = unmatched subjects; group B = matched subjects. (For explanation see text.)

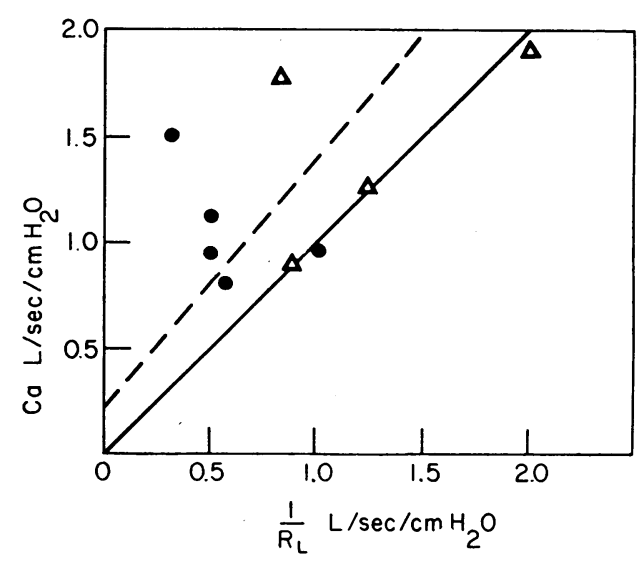

Fig. 5. Comparison between $C_{A}$ and 1/R (total PULMONARY RESISTANCE) FOR THE SAME SUBJECTS. $\Delta=$ pregnant; 0 = postpartum. Solid line is the line of identity. Broken line is the calculated regression line of $\mathrm{C}_{\mathrm{A}}$ on $1 / \mathrm{R}_{\mathbf{L}}$.

since the flow rates and the lung volumes were only approximately similar during the applications of the 2 methods.

\section{Mechanism of changes in airway conductance}

The rise in $\mathrm{C}_{\mathbf{A}}$ at a constant flow during pregnancy clearly indicates an increase in airway crosssectional area. The effects of pregnancy on certain factors known to modify airway size may now be considered.

Lung volume and elastic recoil. It has been demonstrated by Caro, Butler, and DuBois (16) that temporary restriction of thoracic or abdominal mobility by external straps results in an increase in specific $C_{A}$. This increase in specific $C_{A}$ was shown to depend on a diminished $\mathrm{C}_{\mathrm{L}}$. The analogy between external strapping of the abdomen with possible restriction of the diaphragm and restriction by the enlarging uterus suggests a common mechanism for an increased specific $C_{A}$. However, our data do not indicate any change in $\mathrm{C}_{\mathrm{L}}$ during pregnancy. Further, in spite of a higher end normal expiration position of the diaphragm, there can be no true restriction of diaphragm movement since the VC is preserved during pregnancy.

Effects of lung inflation. The volume history of the lung before the measurement of its mechanical properties has been shown to influence both $C_{L}$ and $R_{A}$. Since the lung during pregnancy has a reduced resting volume, this effect might be 
potentiated. However, the sequence of our studies, and particularly the change in $\mathrm{R}_{\mathrm{L}}$ shown after a rest period in the laboratory, do not support this explanation.

Metabolic factors. One important metabolic change during pregnancy is the increased levels of various hormones. These might reduce airway resistance. Three possible hormones might be considered. Progesterone levels rise progressively during pregnancy, and the decreased tone in certain smooth muscles, namely in the ureters, has been attributed to progesterone (17). This effect also occurs at the sixth to seventh month of pregnancy. Thus, progesterone might reduce normal bronchomotor tone.

The production of cortisone and related steroids is also well known to be increased during pregnancy. One may speculate that these steroids also modify normal bronchomotor tone.

Relaxin is known to mobilize cartilaginous structures in pregnant lower mammals (18), and it is conceivable that similar effects occur in pregnant women. However, too little is known about relaxin to permit further discussion of this point.

The possible relationship between hormonal changes during pregnancy and decreased $R_{A}$ is intriguing but speculative.

\section{Dyspnea and work of breathing during pregnancy}

Bader, Bader, and Rose (19) demonstrated a progressive increase in the $\mathrm{O}_{2}$ cost of breathing under standardized patterns of respiration during the last 4 months of pregnancy. These authors suggested that these increased $\mathrm{O}_{2}$ costs of breathing were not related to altered lung mechanics, but rather to increased diaphragmatic work. Our data indicating an unchanged $\mathrm{C}_{\mathbf{L}}$ and reduction in both $R_{L}$ and $R_{A}$ support their view.

The demonstrated reduction in $R_{\mathbf{A}}$ during pregnancy cannot account for the "dyspnea of pregnancy." The reduced $R_{A}$ is, however, probably relevant to the failure of pregnancy to cause respiratory embarrassment in patients with lung resections. Gaensler, Patton, Verstraeten, and Badger (1) studied 7 such patients in whom the vital capacities were reduced to a mean of $1.4 \mathrm{~L}$. The alterations in the static lung volumes during pregnancy were similar to those of normal women. It is reasonable, therefore, to presume that $R_{A}$ was reduced in such patients. Gaensler and associates specifically indicate that these patients did not complain of dyspnea during pregnancy. In these patients, the increased ventilatory demands of pregnancy must be met by rises in the respiratory rate. Thus, a reduced $R_{\mathbf{A}}$ assumes some importance in minimizing the increase in total respiratory work and might possibly relate to the absence of dyspnea.

\section{References}

1. Gaensler, E.A., W. E. Patton, J. M. Verstraeten, and T. L. Badger. Pulmonary function in pregnancy. III. Serial observations in patients with pulmonary insufficiency. Amer. Rev. Tuberc. 1953, 67, 779.

2. Cugell, D. W., N. R. Frank, E. A. Gaensler, and T. L. Badger. Pulmonary function in pregnancy. I. Serial observations in normal women. Amer. Rev. Tuberc. 1953, 67, 568.

3. DuBois, A. B. Resistance to breathing in Handbook of Physiology, sect. 3, vol. 1, Respiration, W. O. Fenn and H. Rahn, Eds. Baltimore, Waverly, 1964, p. 451.

4. Gaensler, E. A. Lung displacement: abdominal enlargement, pleural space disorders, deformities of the thoracic cage in Handbook of Physiology, sect. 3, vol. 2, Respiration, W. O. Fenn and H. Rahn, Eds. Baltimore, Waverly, 1964, p. 1623.

5. Newhouse, M. T., M. R. Becklake, P. T. Macklem, and $M$. McGregor. Effect of alterations in endtidal $\mathrm{CO}_{2}$ tension on flow resistance. J. appl. Physiol. 1964, 19, 745.

6. Prowse, C. M., and E. A. Gaensler. Respiratory and acid-base changes during pregnancy. Anesthesiology 1965, 26, 381.

7. Rubin, A., N. Russo, and D. Goucher. The effect of pregnancy upon pulmonary function in normal women. Amer. J. Obstet. Gynec. 1956, 72, 963.

8. Marshall, R. Objective tests of respiratory mechanics in Handbook of Physiology, sect. 3, vol. 2, Respiration, W. O. Fenn and H. Rahn, Eds. Baltimore, Waverly, 1964, p. 1399.

9. Mead, J. Volume displacement body plethysmograph for respiratory measurements in human subjects. J. appl. Physiol. 1960, 15, 736.

10. Frank; N. R., J. Mead, A. A. Siebens, and C. F. Storey. Measurements of pulmonary compliance in seventy healthy young adults. J. appl. Physiol. 1956, 9, 38.

11. Attinger, E. O., R. G. Monroe, and M. S. Segal. The mechanics of breathing in different body positions. I. In normal subjects. J. clin. Invest. 1956, 35, 904.

12. Mead, J., and E. A. Gaensler. Esophageal and pleural pressures in man, upright and supine. $\mathrm{J}$. appl. Physiol. 1959, 14, 81. 
13. Knowles, J. H., S. K. Hong, and H. Rahn. Possible errors using esophageal balloon in determination of pressure-volume characteristics of the lung and thoracic cage. J. appl. Physiol. 1959, 14, 525.

14. Chiang, S. T., and H. A. Lyons. The effect of postural change on pulmonary compliance. Resp. Physiol. 1966, 1, 99.

15. Ferris, B. G., Jr., J. Mead, and N. R. Frank. Effect of body position on esophageal pressure and measurement of pulmonary compliance. J. appl. Physiol. 1959, 14, 521.

16. Caro, C. G., J. Butler, and A. B. DuBois. Some effects of restriction of chest cage expansion on pul- monary function in man: an experimental study. J. clin. Invest. 1960, 39, 573.

17. Daly, D. F. Maternal physiology in Textbook of Obstetrics, J. C. Ullery and Z. S. R. Hollenbeck, Eds. St. Louis, C. V. Mosby, 1965, p. 56.

18. Bisca, B. V. Medication during labor and delivery in Textbook of Obstetrics, J. C. Ullery, and Z. S. R. Hollenbeck, Eds. St. Louis, C. V. Mosby, 1965, p. 397.

19. Bader, R. A., M. E. Bader, and D. J. Rose. The oxygen cost of breathing in dyspnœic subjects as studied in normal pregnant women. Clin. Sci. 1959, 18, 223. 